\title{
Depression, anxiety and quality of life scores in seniors after an endurance exercise program
} Escores de depressão, ansiedade e qualidade de vida em ídosos após um programa de exercicios aeróbios

\author{
Hanna Karen Moreira Antunes, ${ }^{1,2}$ Sérgío Garcia Stella, ${ }^{2}$ \\ Ruth Ferreira Santos, ${ }^{1}$ Orlando Francisco Amodeu Bueno, ${ }^{1,3}$ \\ Marco Túlio de Mello ${ }^{1,2,3}$
}

\begin{abstract}
Objective: Mood disorders are a frequent problem in old age, and their symptoms constitute an important public health issue. These alterations affect the quality of life mainly by restricting social life. The participation in a regular exercise program is an effective way of reducing or preventing the functional decline associated with aging. The aim of the present study was to examine the effects of fitness-endurance activity (at the intensity of Ventilatory Threshold 1 (VT-1)) in depression, anxiety and quality of life scores in seniors. Methods: The study involved 46 sedentary seniors aged 60-75 (66.97 \pm 4.80$)$ who were randomly allocated to two groups: 1) Control group, which was neither asked to vary their everyday activities nor to join a regular physical fitness program; and 2) Experimental group, whose members took part in an aerobic fitness program consisting of ergometer cycle sessions 3 times a week on alternate days for six months working at a heart rate corresponding to ventilatory threshold (VT-1) intensity. Subjects were submitted to a basal evaluation using the geriatric depression screening scale - GDS, STAI trait/state (anxiety scale) and SF-36 (quality of life scale). Results: Comparing the groups after the study period, we found a significant decrease in depressive and anxiety scores and an improvement in the quality of life in the experimental group, but no significant changes in the control group. Conclusion: The data suggest that an aerobic exercise program at VT-1 intensity suffices to promote favorable modifications in depressive and anxiety scores to improve the quality of life in seniors.
\end{abstract}

Keywords: Depression; Anxiety; Quality of life; Aged; Physical endurance; Exercise therapy/methods

\begin{abstract}
Resumo
Objetivo: Transtornos de humor são problemas freqüentes na população idosa. Seus sintomas representam uma importante questão de saúde pública e afetam substancialmente a qualidade de vida, principalmente por restringir atividades sociais. $A$ participação em um programa de exercícios físicos regulares parece ser efetiva em reduzir e prevenir o declínio funcional decorrente do envelhecimento. O objetivo do presente trabalho foi examinar o efeito de um programa de exercício físico aeróbio na intensidade do limiar ventilatório 1 (VT-1) nos escores indicativos de depressão e ansiedade e na qualidade de vida de idosos saudáveis. Métodos: O estudo envolveu 46 voluntários sedentários saudáveis com idades entre 60-75 (66,97 \pm 4,80), que foram distribuídos aleatoriamente em dois grupos: 1) Controle, que foi orientado a não alterar suas atividades rotineiras e a não se engajar em um programa de exercício físicos e 2) Experimental, que participou de programa de exercício em bicicleta ergométrica, três vezes por semana, em dias alternados, na intensidade do VT-1, por seis meses. Os voluntários foram submetidos a uma avaliação utilizando-se um screening composto pelas escalas: GDS (depressão), STAl traço/estado (ansiedade) e SF-36 (qualidade de vida). Resultados: A comparação dos grupos após o período de estudo revelou que o grupo experimental obteve redução dos escores de depressão e ansiedade e aumento da qualidade de vida, enquanto que no grupo controle não foram observadas alterações. Conclusão: Os dados sugerem que um programa de exercício em bicicleta ergométrica na intensidade do VT-1 é suficiente para promover modificações favoráveis nos escores indicativos de depressão e ansiedade e melhorar a qualidade de vida de idosos.
\end{abstract}

Descritores: Depressão; Ansiedade; Qualidade de vida; Idoso; Resistência física; Terapia por exercício/métodos

\footnotetext{
1 Psychobiology Department, Universidade Federal de São Paulo (UNIFESP), São Paulo (SP), Brazil

2 Psychobiology and Exercise Research Center (CEPE-CENESP), Universidade Federal de São Paulo (UNIFESP), São Paulo (SP), Brazil

3 Conselho Nacional de Desenvolvimento Científico e Tecnológico (CNPQ)
}

Financing: AFIP, CAPES, CEPE/CENESP-UNIFESP, CNPQ and FAPESP (Cepid \#98/14303-3 st).

Conflict of interests: None

Submited: 3 March 2004

Accepted: 31 August 2004

\section{Correspondence}

Hanna Karen Moreira Antunes

Centro de Estudos em Psicobiologia e Exercício

Departamento de Psicobiologia,

Universidade Federal de São Paulo - Escola Paulista de Medicina

R. Marselhesa, 535 - Vila Clementino

04020-060, São Paulo, SP, Brazil

Phone: (55 11) 5572-0177 Fax: (55 11) 5083-6900

E-mail: hannakaren@psicobio.epm.br 


\section{Introduction}

Mood disorders symptoms are characterized by inadequate affective manifestations in terms of intensity, frequency and duration, ${ }^{1}$ of which the best known are depression and anxiety.

These disorders promote alterations that affect the quality of life in seniors, particularly by restricting their social life and gradually reducing their independence. The concept of 'quality of life' is defined as a perceived global satisfaction and satisfaction within a number of key domains with special emphasis on well-being. ${ }^{2}$ An important point is that quality of life is a subjective concept, representing the quest for happiness and pleasure in all aspects of life, and that people have different interpretations of this concept.

Depression and anxiety are significantly prevalent causes of physical illness, psychosocial impairment and mortality throughout the world. These symptoms affect millions of people irrespective of ethnicity, education, gender or income, with the prevalence of depressive disorders ranging from 5 to $25 \%$ and anxiety disorders somewhat lower. ${ }^{3}$

Depression in seniors is associated with increased risk of physical and functional decline, cognitive impairment, institutionalization, frailty, life-threatening malnutrition and weight loss, psychological distress, low self-esteem, negative interpretations of everyday perceptions and nonadherence to pharmacotherapy for chronic conditions. ${ }^{4,5-7}$

Several methodologies have shown associations between physical exercise and improvement in mental health symptoms in various populations. ${ }^{3,8}$ Observational and interventional studies have suggested that regular physical exercise may be associated with reduced symptoms of depression and anxiety, and have consistently found that more active individuals report lower depression scores than more sedentary individuals. ${ }^{9-14}$

Some researchers have studied the effects of increased physical activity on depressive symptoms in clinically depressed and nonclinically depressed populations, and have noted beneficial effects within both groups across a variety of exercise modalities $^{3}$, while others found no significant alterations. ${ }^{15-16}$

Studies of the effects of physical exercise on mood disorders have produced conflicting results, and considering these discrepancies in the literature the aim of the present study was to examine the effects of a fitness-endurance program at the intensity of Ventilatory Threshold 1 (VT-1) on scores for depression, anxiety and quality of life in the elderly.

\section{Methods}

\section{Sample}

Forty-six healthy sedentary male volunteers aged 60-75 $(66.97 \pm 4.80)$ were selected from an initial pool of 118 . The volunteers were randomly allocated to two groups: the control group ( $n=23)$ and the experimental group $(n=23)$. The characteristics of both groups are presented in Table 1.

Members of the control group were asked neither to vary their everyday activities nor to join a fitness program. Subjects were longitudinally monitored through monthly phone calls to maintain contact and keep them informed of the course of the study. They were also informed that although they would not be taking part in the fitness program they could do it after the intervention period for the experimental group.

The experimental group took part in an aerobic fitness program every other day (3 times a week) for six months. Sessions were continuous and initially lasted for 20 minutes being gradually increased up to a maximum of 60 on an ergometric cycle (Life Cycle 9.500 HR), which was prescribed after the ergospirometric evaluation of variations in the subjects' heart rates. In all sessions subjects had their arterial pressure checked and their heart frequency monitored at 5-second intervals using a Polar ${ }^{\circledR}$ Advantage NV. Intensiveness of exercise was prescribed according to the concept of an "anaerobic threshold" proposed by Wasserman and Mac Ilroy (1964) and Wasserman et al. (1986), who suggested that at a certain percentage of maximal power output, oxygen supply will be insufficient for full oxidation of glucose via the glycolytic pathways, resulting in a displacement of pyruvate which is derived from the Krebs cycle and transformed into lactate. ${ }^{17-18}$ The measurement of ventilation, oxygen consumption (VO2) and carbon dioxide production (VCO2), during exercise can detect this 'threshold' or 'ventilatory threshold I (VT-I)', which is indicated by a change in the slope of the ventilatory flow rate (VE) plotted against power. This threshold is usually found between 50 and $60 \%$ of maximal oxygen consumption (VO2 max). Further, a second 'threshold' was also described between 80 and $90 \%$ of VO2 max, when the $V E / V O 2$ ratio suddenly increases, being interpreted as the 'onset of blood lactate-induced acidosis'.

\section{Procedure}

As our criteria for the initial selection, volunteers had to have at least 7 years of schooling and a level of physical fitness, which reflected a sedentary lifestyle (i.e. not habitually doing any physical activity). Individuals were excluded if they did not match the above criteria or if they presented alterations in clinical parameters (illness) or in laboratory exams, or were users of psychotropic drugs or of any pharmaceutical drug to which physical activity is contraindicated, or if they had been recently submitted to surgery. As part of the selection process we conducted resting and stress electrocardiograms to ensure the volunteers' cardiovascular health.

The selection process also involved testing using the Mini Mental State Exam (MMSE) by Folstein et al. (1975) - divided in five sub-tests (orientation, immediate memory, attention and

Table 1 - Schooling, socioeconomic and marital status indicators

\begin{tabular}{lcccc}
\hline \multirow{2}{*}{ Variables } & \multicolumn{2}{c}{ Control } & \multicolumn{2}{c}{ Experimental } \\
\cline { 2 - 5 } & $\mathrm{n}$ & $\%$ & $\mathrm{n}$ & $\%$ \\
\hline Schooling & & & & \\
University & 8 & 34.78 & 13 & 56.52 \\
Technical & 2 & 8.69 & 2 & 8.69 \\
Secondary & 11 & 47.82 & 4 & 17.39 \\
Elementary & 1 & 4.34 & 3 & 13.04 \\
Elementary not concluded & 1 & 4.34 & 1 & 4.34 \\
\hline Total & 23 & 100 & 23 & 100 \\
\hline
\end{tabular}

\begin{tabular}{lcccc}
\hline Socioeconomic status & & & & \\
A & 5 & 21.73 & 9 & 39.13 \\
B & 5 & 21.73 & 7 & 30.43 \\
C & 12 & 52.17 & 6 & 26.08 \\
D & 1 & 4.34 & 1 & 4.34 \\
E & 0 & 0 & 0 & 0 \\
\hline Total & 23 & 100 & 23 & 100 \\
\hline Marital Status & & & & \\
Married & 14 & 60.86 & 20 & 86.95 \\
Single & 3 & 13.04 & 1 & 4.34 \\
Widower & 3 & 13.04 & 1 & 4.34 \\
Separated/ divorced & 3 & 13.04 & 0 & 0 \\
Co-habiting & 0 & 0 & 1 & 4.34 \\
\hline Total & 23 & 100 & 23 & 100 \\
\hline
\end{tabular}

Descriptive analyze by Frequency tables. No statistical differences between groups were observed. 
calculation, recall and language). ${ }^{19}$ Our MMSE cut-off score was 24 points. ${ }^{20}$

All methods and procedures were approved by the Research Ethics Committee of the Universidade Federal de São Paulo (\#207/01). The nature of the study, its aims and possible risks were carefully explained to all volunteers beforehand and they gave their informed consent.

\section{Experimental protocol}

The questionnaires were individually applied in a quiet room. Before the beginning, the procedures were explained and the volunteers were asked to respond honestly.

The following questionnaires were applied:

1) GDS (Geriatric Depression Scale) - Instrument consisting of 30 items frequently used to detect depression in seniors. Several studies have found that the GDS provides valid and reliable measures to evaluate depression. ${ }^{21-22}$

2) STAI (Spielberger State -Trait Anxiety Inventory) - a selfrated questionnaire divided in two parts: anxiety-trait (referring to personality aspects) and anxiety-state (referring to systemic aspects of the context), translated and validated in Brazilian population. Each part contains twenty statements. Responses are in a 1-4 scale. Anxiety-state refers to how individuals feel 'at the moment' and anxiety-trait to how they 'generally feel'. Each part varies from 20 to 80 points, and the scores indicate low (0-30), medium (31-49) or high (50 or more) anxiety levels. ${ }^{23-25}$

3) SF-36 - Health Research - Generic Questionnaire for Evaluation of Quality of Life 'Medical Outcomes Study SF-36', translated and validated in Brazilian population. This is a multidimensional instrument consisting of 36 items to generically evaluate the quality of life scored on 8 multi-item scales: physical functioning, role-physical, pain, general health perception, vitality, social functioning, role-emotional, mental health, plus a one-item measure of self-evaluated change in health status in the past year. ${ }^{26}$

\section{Statistical analysis}

Statistical analysis was performed using Statistics for Windows ${ }^{\circledR}$ version 5.5 . For the qualitative data it was used a descriptive analysis with percentual values determined by frequency tables. One-way analysis of variance (ANOVA) was used for repeated measures ( $2 x$ time/ $2 x$ group) to determine the effect of intervention periods, being used a Wald post-hoc test when necessary. The minimum significance level was set at $5 \%$, and data were presented as 'mean \pm standard deviation'.
Table 2 - Initial sample data. Age, body mass, height and BMI (Body Mass Index - weightheight')

\begin{tabular}{lcc}
\hline \multicolumn{1}{c}{ Variables } & Control & Experimental \\
\hline Age & $65.86 \pm 3.80$ & $68.08 \pm 5.49$ \\
Body mass $(\mathrm{Kg})$ & $76.38 \pm 11.10$ & $77.56 \pm 13.45$ \\
Height $(\mathrm{m})$ & $1.67 \pm 0.58$ & $1.69 \pm 0.85$ \\
BMI & $27.17 \pm 3.09$ & $27.06 \pm 3.75$ \\
\hline
\end{tabular}

No statistical differences between groups were observed.

\section{Results}

There were no dropouts neither in the experimental nor in the control group and all volunteers concluded the experimental protocol. Table 1 shows schooling, socioeconomic and marital status indicators for the sample and Table 2 show the initial sample data. No significant between-group differences were observed.

Table 3 shows the results in terms of depressive and anxiety scores, and the results of the medical outcomes study 36-item short-form health survey (SF-36). ANOVA analysis has not detected differences between groups in the pre-intervention condition. The questionnaires which evaluate the volunteers' mood showed a significant decrease in scores for anxiety trait and state and scores for depression. For anxiety, the level classification of the experimental group changed from medium to low. For depression, ANOVA detected the following differences: factor group $\left[F_{(144)}=4.85 ; p=0.03\right]$, factor time $\left[F_{(1,44)}=20.55 ; p<0.01\right]$, interaction between factors was observed $\left[F_{(1,44)}=12.62 ; p<0.01\right]$; as to anxiety trait a significant difference in factor time was observed $\left[F_{(1,44)}=40.77\right.$; $p<0.01]$ and interaction between factors $\left[F_{(1,44)}=15.65\right.$; $p<0.01]$, no significant differences was observed to factor group $\left[F_{(1,44)}=0.40 ; p=0.52\right]$; for anxiety state a significant difference in factor time was observed $\left[F_{(1,44)}=8.63 ; p<0.01\right]$ and interaction between factors $\left[F_{(1,44)}=9.18 ; p<0.01\right]$; no significant differences were observed for the factor group $\left[F_{(1,44)}=0.34 ; p=0.56\right]$. Figures 1,2 and 3 also show these results.

In relation to scores on the SF-36 health research questionnaire on quality of life, we found significant differences on all 8 dimensions. The ANOVA analysis detected differences regarding mean values for all 8 dimensions: factor group $\left[F_{(1,4)}=8.66\right.$; $\mathrm{p}<0.01]$ and factor time $\left[\mathrm{F}_{(1,44)}=14.89 ; \mathrm{p}<0.01\right]$, interaction between factors was observed $\left[F_{(1,44)}=15.86 ; p<0.01\right]$ regarding Physical functioning dimension a significant difference

Table 3 - Depression, anxiety and quality of life scores

\begin{tabular}{|c|c|c|c|c|c|}
\hline & \multirow[t]{2}{*}{ Variables } & \multicolumn{2}{|c|}{ Contral } & \multicolumn{2}{|c|}{ Experimental } \\
\hline & & Before & After & Before & After \\
\hline GDS & Depression & $7.73 \pm 4.56$ & $7.04 \pm 3.83$ & $7.95 \pm 5.66$ & $2.21 \pm 2.43^{*} \ddagger$ \\
\hline \multirow[t]{2}{*}{ STAI (Anxiety) } & Trait & $37.13 \pm 6.89$ & $34.26 \pm 4.55^{\star}$ & $40.78 \pm 9.21$ & $28.56 \pm 5.50^{*} \ddagger$ \\
\hline & State & $33.00 \pm 5.55$ & $33.08 \pm 5.53$ & $35.08 \pm 5.34$ & $29.52 \pm 4.85 " \ddagger$ \\
\hline \multirow[t]{9}{*}{ SF-36 } & Mean & $75.18 \pm 11.57$ & $74.95 \pm 10.59$ & $75.40 \pm 14.07$ & $89.91 \pm 4.36^{\prime \prime} \ddagger$ \\
\hline & Physical functioning & $90.65 \pm 11.99$ & $91.08 \pm 6.56$ & $91.95 \pm 8.35$ & $97.82 \pm 2.53^{*} \ddagger$ \\
\hline & Role-physical & $78.26 \pm 33.11$ & $72.82 \pm 30.99$ & $72.82 \pm 35.28$ & $100 \pm 0.00 * \ddagger$ \\
\hline & Pain & $58.82 \pm 16.72$ & $60.95 \pm 11.75$ & $65.08 \pm 14.90$ & $77.60 \pm 15.04 * \ddagger$ \\
\hline & General health perception & $75.26 \pm 9.88$ & $76.08 \pm 7.53$ & $72.00 \pm 12.24$ & $81.04 \pm 8.12^{*} \ddagger$ \\
\hline & Vitality & $69.78 \pm 9.94$ & $73.04 \pm 9.38$ & $72.17 \pm 13.63$ & $85.65 \pm 4.59^{*} \ddagger$ \\
\hline & Social functioning & $76.08 \pm 19.91$ & $73.36 \pm 15.21$ & $72.28 \pm 16.40$ & $87.50 \pm 12.50^{*} \ddagger$ \\
\hline & Role-emotional & $75.35 \pm 36.54$ & $71.01 \pm 35.26$ & $79.71 \pm 34.43$ & $98.55 \pm 6.944^{*} \ddagger$ \\
\hline & Mental health & $77.21 \pm 8.97$ & $81.21 \pm 11.53$ & $77.21 \pm 13.45$ & $90.95 \pm 3.24 * \ddagger$ \\
\hline
\end{tabular}

Data were presented as mean \pm standard deviation. Before $=$ before treatment intervation. After $=$ after the six month period of study. ANOVA for repeated measurements with Wald post-hoc test. $\neq$ different between groups control group, $p \leq 0.05$. * Different of baseline condition for the same group, $p \leq 0.05$. 


\section{GDS}

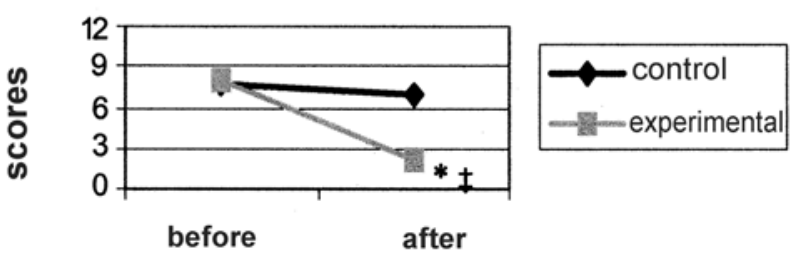

Figure 1 - Depression scores

Effects of period of study on scores in control and experimental groups (before and after the six month period).

Each line is a mean for 23 volunteers. Black line = control group; Gray line $=$ experimental group.

* different of before condition for the same group, $p \leqslant 0.05$. $\ddagger$ different for post-intervention condition between groups, $p \leqslant 0.05$ (ANOVA for repeated measurements with Wald post-hoc test)

in factor group was observed $\left[F_{(1,44)}=5.49 ; p<0.02\right]$; no differences in factor time were observed $\left[F_{(1,44)}=3.57 ; p=0.06\right]$. No interaction between values was observed. For the RolePhysical dimension a significant difference in factor time $\left[F_{(1,44)}=5.18 ; p=0.02\right]$ and interaction between factors $\left[F_{(1,44)}=11.67 ; p<0.01\right]$, no significant differences were observed for the factor group $\left[F_{(1,44)}=2.40 ; p=0.12\right]$; for the Pain dimension a significant difference in factor group was observed $\left[F_{(1,44)}=12.30 ; p<0.01\right]$ and factor time $\left[F_{(1,44)}=6.57 ; p<0.01\right]$, no significant differences was observed between factors were observed. For the General Health Perception dimension a significant difference in factor time was observed $\left[F_{(1,44)}=8.49\right.$; $p<0.01]$ and interaction between factors $\left[F_{(1,44)}=5.89\right.$; $p<0.01]$, no significant differences were observed for the factor group $\left[F_{(1.44)}=0.13 ; p=0.71\right]$. For the Vitality dimension a significant difference in factor group was observed $\left[F_{(1,44)}=10.75\right.$; $p<0.01]$ and factor time $\left[F_{(1.44)}=20.99 ; p<0.01\right]$, interaction between factors was observed $\left[\mathrm{F}_{(1,44)}=7.82 ; \mathrm{p}<0.01\right]$. For the Social Functioning a significant difference in factor time was observed $\left[\mathrm{F}_{(1,44)}=8.45 ; \mathrm{p}<0.01\right]$ and interaction between factors $\left[F_{(1,44)}=17.41 ; p<0.01\right]$, no significant differences were for the factor group $\left[F_{(1,44)}=1.45 ; p=0.23\right]$. For the Role-emotional dimension a significant difference in factor group was

\section{Anxiety State}

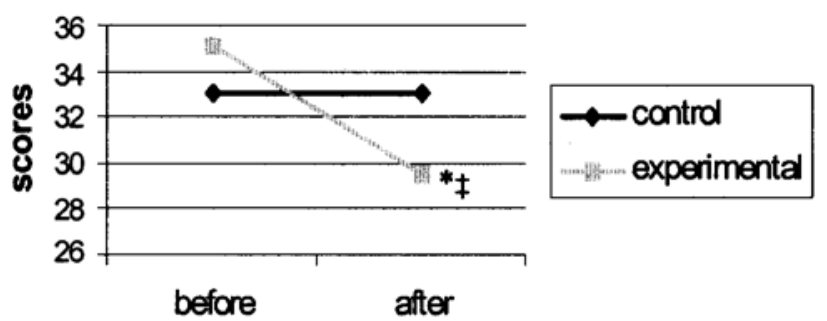

Figure 3 - Anxiety State scores

Effects of period of study on anxiety state scores in control and experimental groups (before and after the six-month period).

Each line is a mean for 23 volunteers. Black line = control group; Gray line $=$ experimental group.

" different of before condition for the same group, $p \leqslant 0.05$. $\ddagger$ different for post-intervention condition between groups, $p \leqslant 0.05$ (ANOVA for repeated measurements with Wald post-hoc test)

\section{Anxiety Trait}

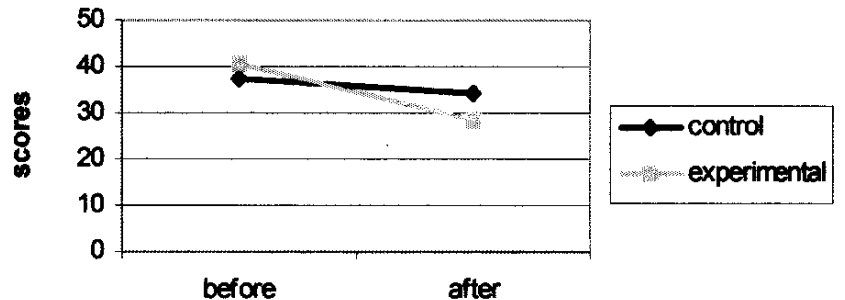

Figure 2 - Anxiety Trait scores

Effects of period of study on anxiety trait scores in control and experimental groups (before and after the six-month period). Each line is a mean for 23 volunteers. Black line $=$ control group; Gray line = experimental group. ${ }^{*}$ different of before condition for the same group, $p \leq 0.05$. $¥$ different for postintervention condition between groups, $p \leq 0.05$ (ANOVA for repeated measurements with Wald post-hoc test)

observed $\left[F_{(1,44)}=4.42 ; p=0.04\right]$ and interaction between factors $\left[F_{(1,44)}=5.29 ; p=0.02\right]$, no significant differences were observed for the factor time $\left[F_{(1,44)}=2.06 ; p=0.15\right]$. For the Mental Health dimension a significant difference in factor group was observed $\left[F_{(1,44)}=4.21 ; p=0.04\right]$ and factor time $\left[F_{(1,44)}=24.77 ; p<0.01\right]$, interaction was observed between factors $\left[F_{(1.4)}=7.46 ; p<0.01\right]$. Figure 4 shows mean values for all 8 dimensions.

\section{Discussion}

Several studies have shown that regular physical exercise has a favorable influence on symptoms of anxiety and depression, ${ }^{27-29}$ although a certain minimum level of activity is required for these interventions to be effective. ${ }^{30}$

Our study found no significant alterations between the groups before the intervention period. Comparing pre- and postintervention periods, our study found significantly decreased scores for depression and anxiety in the experimental group. These results replicates previous literature that contains reports of improvement of these variables after aerobic exercise programs compared to maintenance of high scores in individuals who remained sedentary. ${ }^{9-10,12}$ We also found an improvement in the anxiety trait in the control group. The fact

Ceneral Scores of SF-36

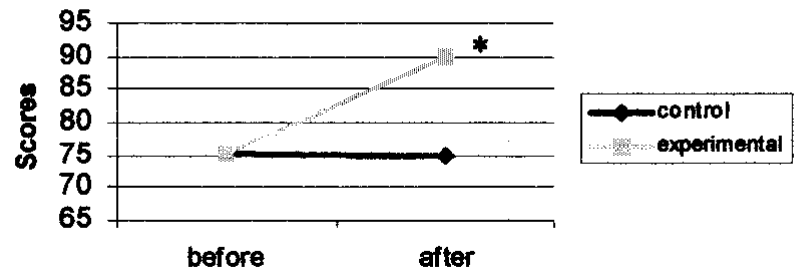

Figure 4 - Quality of life scores

Overall scores on SF-36. Effects of period of study on SF-36 overall scores in control and experimental group (before and after the six-month period). Each line is a mean of 23 volunteers. Black line = control group; Gray line $=$ experimental group. ANOVA for repeated measurements with Wald post-hoc test, * different of before condition for the same group, $p \leq 0.05$. $¥$ different for post-intervention condition between groups, $p \leq 0.05$. 
that this group has participated in this study may have motivated the adoption of better lifestyle habits that had a favorable impact on every aspect of life.

A number of plausible behavioral, social, psychological and physiological mechanisms through which exercise may ameliorate depression symptoms have been suggested, but few have been systematically examined. ${ }^{31}$

Exercise may affect central monoamine functioning by producing more basal free fatty acids and raising free tryptophan levels, which could boost serotonin synthesis by raising central nervous system availability of its amino acid precursor. ${ }^{32-33}$

On the other hand, imbalances in the Hypothalamicpituitary-adrenal (HPA) axis have been linked to depression. ${ }^{34}$ Depression is usually marked by an hyperactivity of the HPA axis, and exercise may lead to an attenuation of the HPA axis response to stress, therefore exercise may partially reduce depression by regulating the HPA axis response to stress. ${ }^{35}$ However, of note, not all depressed individuals show HPA axis hyperactivity. ${ }^{31}$

The role of B-endorphin, an endogenous opioids, in exercise treatment for depression has also been considered. It is well known that exercise leads to a B-endorphin surge into the blood stream to calm the sympathetic nervous system and provide analgesic relief from pain associated with strenuous exercise. Preliminary support for the hypothesis that Bendorphin surges mediate the antidepressant effects of exercise is provided by studies showing that post-exercise mood elevations are associated with increases in basal B-endorphin levels and are attenuated by the administration of naloxone (an opioid antagonist). ${ }^{36}$ Moreover, B-endorphin may influence the release of Dopamine and therefore activate pleasure and satisfaction areas in the brain. An exercise trial with nonclinically depressed human participants found that decreases in depressive symptomatology were accompanied by decreases in plasma B-endorphin levels. ${ }^{37}$ There is evidence of the link between $\beta$-endorphin levels and depression, but it is less clear. Some authors suggest that B-endorphin may be best interpreted as a marker for stress in depressed individuals. ${ }^{31}$

In addition, regular physical exercise may enhance health, facilitate and foster social contact, and favorably affect the quality of life, thus leading to improved social life and interaction, ${ }^{38}$ Regular physical exercise motivates people to adopt better lifestyle habits and is an alternative treatment for stress, which has favorable impacts on every aspect of life. Perhaps it was the total sum of these alterations associated with lower depression and anxiety scores, which improved the quality of life of our volunteers.

According to Blumenthal et al., exercise training programs may be seen as a therapeutic alternative to antidepressants when treating depression in seniors, although antidepressants may facilitate quicker initial therapeutic response. ${ }^{39}$

An important aspect observed in this research was the fact that there were no dropouts neither in the experimental nor in the control group. This specific population and age group shows fidelity, dedication, responsibility and determination.

Another important aspect in relation to the methodology applied is that the indiscriminate use of these questionnaires with insufficient criteria, guidelines or defined aims does not provide reliable information for the diagnosis of mood disorders. Another important aspect is the decision on a cut-off score, being crucial here the individual context, as well as the observation of population variability. Otherwise, the epidemiological indices will vary widely. Therefore, these scales are efficient and provide an index of symptom severity, but should not be considered as substitutes for the diagnosis by clinical interview.

\section{Conclusion}

The data showed that an endurance-based physical exercise program prescribed at VT-1 intensity using an ergometer cycle was sufficient to promote favorable modifications in scores for depression and anxiety and improvement of quality of life in seniors. This suggests that regular physical exercise may be considered as an alternative to non-medication means of improving mood states and it is an underutilized adjunct to currently accepted pharmacological and psychological therapies.

\section{Acknowledgements}

The authors are grateful to AFIP, CAPES, CEPE/CENESP-UNIFESP, CNPQ and FAPESP for the financial support, and to the two anonymous reviewers for the suggestions to the manuscript. The valuable statistical comments of Prof. Ana Amelia Benedito Silva were greatly appreciated.

\section{References}

1. Piccoloto N, Wainer R, Benvegnú L, Juruena M. Curso e prognóstico da depressão. Revisão comparativa entre os transtornos do humor. Rev Psiquiatr Clín. 2000;27(2). Available from: http:// www.hcnet.usp.br/ipq/revista/r27(2)/art93.htm

2. Hornquist JO. Quality of life: concept and assessment. Scand J Soc Med. 1990;18(1):69-79.

3. Paluska AS, Schwenk TL. Physical activity and mental health: current concepts. Sports Med. 2000;29(3):167-80.

4. Gallo JJ, Lebowitz BD. The epidemiology of common late-life mental disorders in the community: themes for the new century. Psychiatr Serv. 1999;50(9):1158-66

5. Matos e Souza FG. Tratamento da depressão. Rev Bras Psiquiatr. 1999;21(Supl 1):S18-23.

6. Montano CB. Primary care issues related to the treatment of depression in elderly patients. J Clin Psychiatry. 1999;60 Suppl 20:45-51.

7. Cohen GD. Depression in late life. An historic account demonstrates the importance of making the diagnosis. Geriatrics. 2002;57(12):38-9

8. Fox KR. The influence of physical activity on mental well-being. Public Health Nutr. 1999;2(3A):411-8.

9. Bhui K, Fletcher A. Common mood and anxiety states: gender differences in the protective effect of physical activity. Soc Psychiatry Psychiatr Epidemiol. 2000;35(1):28-35.

10. Moore KA, Babyak MA, Wood CE, Napolitano MA, Khatri P, Craighead WE, et al. The association between physical activity and depression in older depressed adults. J Aging Phys Act. 1999; 7:55-61

11. Blumenthal JA, Babyak MA, Moore KA, Craighead WE, Herman S, Khatri $P$, et al. Effects of exercise training on older patients with major depression. Arch Intern Med. 1999;159(19):2349-56.

12. Ruuskanen JM, Ruophila I. Physical activity and psychological well-being among people aged 65 to 84 years. Age Ageing. 1995;24(4):292-6

13. Weyerer S. Physical inactivity and depression in the community: evidence from the Upper Bavarian Field Study. Int J Sports Med. $1992 ; 13(6): 492-6$.

14. Martisen EW. Benefits of exercise for the treatment of depression. Sports Med. 1990;9(6):380-9.

15. King AC, Taylor CB, Haskell WL, DeBusk RF. Influence of regular aerobic exercise on psychological health: a randomized controlled trial of health middle-aged adults. Health Psychol. 1989;8(3):305-24.

16. Cramer SR, Neiman DC, Lee JW. The effects of moderate exercise training on psychological well-being and mood state in women. J Psychosom Res. 1991;35(4-5):437-49. 
17. Wasserman K, Macllroy MB. Detecting the threshold of anaerobic metabolism in cardiac patients during exercise. Am J Cardiol. $1964 ; 14: 844-52$

18. Wasserman K, Beaver WL, Whipp BJ. Mechanisms and patterns of blood lactate increase during exercise in man. Med Sci Sports Exerc. 1986;18(3):344-52.

19. Folstein MF, Folstein SE, McHugh PR. "Mini-mental state:" a practical method for grading the cognitive state of patients for the clinician. J Psychiatr Res.1975;12(3):189-98.

20. Tombaugh TN, McIntyre NJ. The mini-mental state examination: a comprehensive review. J Am Geriatr Soc. 1992;40(9):922-35.

21. Yesavage JA, Brink TL, Rose TL, Lum O, Huang V, Adey M, et al. Development and validation of a geriatric depression screening scale. A preliminary report. J Psychiatr Res. 1982-83;17(1):37-49.

22. Almeida OP, Almeida SA. [Reliability of the Brazilian version of the abbreviated form of Geriatric Depression Scale (GDS) short form]. Arq Neuropsiquiatr. 1999;57(2-B):421-6. Portuguese.

23. Spielberger CD, Gorsuch RL, Lushene E. Manual for the State-Trait Anxiety Inventory ("Self-Evaluation Questionnaire"). Palo Alto, CA: Consulting Psychologist Press; 1970.

24. Andreatini R, Seabra ML. A estabilidade do IDATE-traço: avaliação após cinco anos. Rev ABP-APAL. 1993;15(1):21-5.

25. Gorenstein C, Andrade L. Validation of a Portuguese version of the beck depression inventory and the state-trait anxiety inventory in Brazilian subjects. Braz J Med Biol Res. 1996;29(4):453-7.

26. Ciconelli RM. Tradução para o português e validação do questionário genérico de avaliação de qualidade de vida "medical outcomes study 36-item short-form health survey (SF-36)" [tese]. São Paulo: Universidade Federal de São Paulo; 1997.

27. Orwin A. The running treatment: a preliminary communication on a new use for an old therapy (physical activity) in the agoraphobic syndrome. Br J Physchiatry. 1973;122(567):175-9.

28. Carrieri-Kohlman V, Gormley JM, Douglas MK, Paul SM, Stulbarg MS. Exercise training decrease dyspnea and the distress and anxiety associated with it. Monitoring alone may be as effective as coaching. Chest. 1996;110(6):1526-35.

29. Byrne A, Byrne DG. Effect of exercise on depression, anxiety and other mood states: a review. J Psychosom Res. 1993;37(6):565-74.

30. Annesi JJ. Effects of minimal exercise and cognitive behavior modification on adherence, emotion change, self-image, and physical change in obese women. Percept Mot Skills. 2000;91(1):322-36.

31. Brosse AL, Sheets ES, Lett HS, Blumenthal JA. Exercise and the treatment of clinical depression in adults: recent findings and future directions. Sports Med. 2002;32(12):741-60.

32. Strüder HK, Weicker H. Physiology and pathophysiology of the serotonergic system and its implications on mental and physical performance. Part I. Int J Sports Med. 2001;22(7):467-81.

33. Strüder HK, Weicker H. Physiology and pathophysiology of the serotonergic system and its implications on mental and physical performance. Part II. Int J Sports Med. 2001;22(7):482-97.

34. Akil H, Haskett RF, Young EA, Grunhaus L, Kotun J, Weinberg V, et al. Multiple HPA profiles in endogenous depression: effect of age and sex on cortisol and beta-endorphin. Biol Psychiatry. 1993;33(2):73-85.

35. Buckworth J, Dishman RK. Exercise psychology. New York: Human Kinetics; 2002.

36. Janal MN, Colt EW, Clark WC, Glusman M. Pain sensitivity, mood and plasma endocrine levels in man following long-distance running: effects of naloxone. Pain. 1984;19 (1):13-25.

37. Lobstein DD, Rasmussen CL. Decreases in resting plasma betaendorphin and depression scores after endurance training. J Sports Med Phys Fitness. 1991;31(4):543-51.

38. Resnick B. A seven-step approach to starting an exercise program for older adults. Patient Educ Couns. 2000;39(2-3):243-52.

39. Blumenthal JA, Babyak MA, Moore KA, Craighead WE, Herman S, Khatri $P$, et al. Effects of exercise training on older patients with major depression. Arch Intern Med. 1999;159(19):2349-56. 